\title{
DYNAMIC SPATIAL MODELING APPROACH FOR ESTIMATION OF INTERNAL PHOSPHORUS LOAD
}

\author{
JEHNG-JUNG KAO ${ }^{\circledR}$, WANG-LONG LIN and CHENG-HSIEH TSAI \\ Institute of Environmental Engineering, National Chiao Tung University, 75 Po-Ai Street, Hsinchu, \\ Taiwan 30039, China
}

(Received September 1996; accepted in revised form June 1997)

\begin{abstract}
The effect of the pollution load generated internally from a reservoir on the effectiveness of an eutrophication control plan is significant and has gained increasing attention recently. Accurate estimation of the internal load is difficult because of its spatial and temporal variation. A procedure using a dynamic spatial modeling approach is proposed to improve the estimation. A case study of Posan off-stream reservoir is described to demonstrate the implemementation of the procedure for data collection and model preparation, field sampling planning and investigation, laboratory analysis for phosphorus releasing rates, model integration of AGNPS and WASP, calibration and verification of the integrated model, and the internal load estimation. The procedure is expected to provide appropriate temporal and spatial phosphorus internal load estimation for an off-stream reservoir. (C) 1998 Elsevier Science Ltd. All rights reserved
\end{abstract}

Key words-internal load, nonpoint-source pollution, dynamic modeling, water-quality model, phosphorus releasing rate, model integration, off-stream reservoir

\section{INTRODUCTION}

Eutrophication control for a reservoir or lake has gained increasing attention recently. Contamination generated from the upstream development and human activities introduces a significant amount of nutrients into a reservoir and, thus, accelerates the eutrophication process, spoils the public water resources, and requires costly remediations. Phosphorus and nitrogen are major limit factors of eutrophication. From previous field investigations for reservoir eutrophication in Taiwan (Wu et al., 1992), available nitrogen is, however, much more than available phosphorus in a reservoir, and phosphorus is, therefore, generally considered as the indicator of eutrophication.

There are two sources of phosphorus for a reservoir or lake: external and internal loads. External loads come from the point or nonpointsource pollutants and are carried by runoff from storm events. Internal loads are mostly from the phosphorus released from benthos of the water body. Phosphorus in the water body is presented in both solid and liquid phases. Solid-phase phosphorus is mostly attached on the suspended particles of point or nonpoint-source pollutants. Some of the particles, after being brought into the water body, settle and become parts of benthic sediment. The phytoplank-

*Author to whom correspondence should be addressed [Tel: + 886-3-5731869, Fax: + 886-3-5725958, E-mail: jjkao@green.ev.nctu.edu.tw]. ton dead residuals of benthos contributes also some solid-phase phosphorus in water bodies (Jacoby et al., 1982). Soluble phosphorus is dissolved from the phosphorus adsorbed on the suspended particles or released from benthos.

Particles and phosphorus could be released from benthos through physical, chemical, or biological disturbances and processes (Holdren and Armstrong, 1980; Rossi and Premazzi, 1991; Dillon and Evans, 1993). Such internal loads contribute a significant amount of phosphorus nutrients in some seasons for a water body, even when external pollution inputs are extremely limited (Freedman and Canale, 1977; Rossi and Premazzi, 1991). Jacoby et al. (1982) estimated that the internal phosphorus released from benthic sediment is approximately $20-50 \%$ of that from external loads. It should be noted that the sediment physiochemical characteristics vary seasonally and cause phosphorus adsorption and desorption phenomena (Jacoby et al., 1982; Istvanovics, 1988). In some seasons, phosphorus is adsorbed instead of released from the sediment. In addition to the seasonal change, geographic location as well as different portions of a reservoir would characterize different phosphorus releasing rates (Jacoby et al., 1982). Previous local studies for eutrophication were mostly focused on the water quality and external loads only, and the internal load was rarely explored, especially for an off-stream reservoir, due to sampling and modeling difficulties, although the importance of the internal load estimation had been stated in previous research $(\mathrm{Wu}$ et al., 
1992). The present study was, therefore, initiated to explore an adequate procedure for estimating the internal load.

Three methods for internal load estimation are generally adopted: (1) using representative sampling data to determine the releasing rate, (2) using a simple mass balance calculation to estimate the overall releasing rate, and (3) applying a statistical method. These methods, however, can not practically reveal the spatial distribution and dynamic temporal variation in detail. A dynamic spatial modeling approach with field sampling data was, therefore, explored in this study for simulating the dynamic behavior of the benthic sediment adsorption and desorption of phosphorus.

The procedure adopted in this work for phosphorus internal loading estimation and simulation consists of five major steps: data collection and model preparation; sampling planning and field investigation; laboratory analysis for phosphorus releasing rates; model integration, calibration, verification and simulation; and internal load estimation. In the following sections, these steps are described. The case study of an off-stream reservoir is then presented to exemplify the proposed procedure as well as to demonstrate the manipulation for model integration, multiple step calibration, etc.

\section{DATA COLLECTION AND MODELING PREPARATION}

\section{The study area}

Some areas in Taiwan lack a suitable location to build a general reservoir and have to apply an off-stream method to re-direct the stream flow to a reservoir that is not on the stream network. This kind of off-stream reservoir differs from the general one for pollution load estimation. Pollution loads from the watershed of the reservoir as well as the loads on the inflow channel must be analyzed simultaneously and, therefore, increase the complexity of modeling simulation. The study area was the Posan off-stream reservoir located in Hsinchu, Taiwain, China. The location of the reservoir and inflow channel, Chutong Channel, is illustrated in Fig. 1. The reservoir is used for the supply of public drinking water. It has an area of $60.2 \mathrm{ha}$ with effective storage of up to $5,350,000 \mathrm{~m}^{3}$. Chutong channel is the inflow channel that transfers water from Sapin river to the reservoir and irrigates agricultural areas within Chutong watershed. The channel is $13.36 \mathrm{~km}$ in length, of which $6635 \mathrm{~m}$ is closed channel and $6501 \mathrm{~m}$ is open channel. The water quality of total phosphorus in the reservoir is around $20-40 \mathrm{ppb}$. Based on Carlson (1977) standard, it is in eutrophy status and requires attention for water-quality control. The main sources of nutrients come from the water transferred from the Chutong channel, external sources within the watershed for the reservoir, and the internal load within the reservoir itself.
Before the internal loading can be properly simulated, external loads must be estimated. Unfortunately, currently no single model is appropriate to be utilized for simulating both external and internal loads. Two separate models, AGNPS (Young et al., 1987) and WASP (Ambrose et al., 1993), were selected, therefore, for external and internal loading simulations, respectively. The two models are briefly described below, while detailed information for the models is available in the original documents.

\section{AGNPS}

AGNPS is a physical-based model developed for evaluating upstream land erosions and water quality to meet the requirement of US federal regulations. It is a grid-based model for single storm-event simulation. Watershed are divided into numerous rectangle grids which are not necessary of the same size. Hydrology, soil erosion, nutrient, and sediment movement are computed for each model grid and for inter-grid transport. Runoff data are determined by the SCS curve (Wischmeier and Smith, 1978) or unit hydrograph methods. Upland and channel erosion from a storm event is determined primarily based on the Universal Soil Loss Equation (Wischmeier and Smith, 1978). Total nitrogen (TN), total phosphorus (TP), and chemical oxygen demand are the water quality parameters analyzed in the model.

\section{$W A S P$}

WASP is a dynamic compartment model developed by US EPA (Ambrose et al., 1993) that can simulate the water quality of water column and underlying benthos for an aquatic system using the finite segmentation method. A water body is divided into layers of segments. With a proper segmentation, the model is applicable for a three-dimensional dynamic simulation. The model can analyze phosphorus and seven other water-quality parameters. This study concentrated mainly on the phytoplankton, organic, and inorganic phosphorus. The phytoplankton growth, death, settling, and mineralization are considered by the model. The internal loading is determined by phosphorus releasing rates, settling rates, transfer coefficients, and concentration gradient between the sediment and bulk water phase. Important equations related to phytoplankton and the phosphorus cycle are listed below.

Phytoplankton kinetics. Chlorophyll- $a$ is used as the aggregated variable for phytoplankton, and the major kinetics equation is expressed below:

$$
\frac{\partial C}{\partial t}=\left(C_{\mathrm{g}}-C_{\mathrm{d}}-C_{\mathrm{s}}\right) C
$$

where $C$ is the phytoplankton concentration (mg-C/ liter), $C_{\mathrm{g}}$ is the specific growth rate ( $1 /$ day), $C_{\mathrm{d}}$ is death rate (1/day), and $C_{s}$ is the settling rate $(1 /$ day). The specific growth rate is computed by $C_{\mathrm{gm}} \cdot T_{\mathrm{c}} \cdot L \cdot N$, where $C_{\mathrm{gm}}$ is the maximum specific growth rate at optimum light and nutrients, $T_{\mathrm{c}}$ is the temperature 
adjustment factor, $L$ is the light limitation factor, and $N$ is the nutrient limitation factor as a function of dissolved inorganic phosphorus and nitrogen. Death rate ( $1 /$ day) is determined by $E_{\mathrm{r}}+D_{\mathrm{pt}}+G \cdot Z$, where $E_{\mathrm{r}}$ is the temperature corrected endogenous respiration rate, $D_{\mathrm{pr}}$ is the death rate caused by parasitization or toxic materials, $G$ is the grazing rate on phytoplankton per unit zooplankton population ((liters/mgCarbon)/day), and $\mathcal{Z}$ is the herbivorous zooplankton population grazing on phytoplankton (mg-C/liter). The settling rate ( $1 /$ day) is computed by $V / D$, where $V$ is the net settling velocity of phytoplankton (m/day) and $D$ is the depth of water column of model segment.

The phosphorus cycle. The phosphorus cycle is mainly simulated by the following three equations for phytoplankton, organic and inorganic phosporus, respectively:

$$
\begin{aligned}
& \frac{\partial\left(C \cdot a_{\mathrm{pc}}\right)}{\partial t}=C_{\mathrm{g}} \cdot a_{\mathrm{pc}} \cdot C-C_{\mathrm{d}} \cdot a_{\mathrm{pc}} \cdot C-\frac{V}{D} a_{\mathrm{pc}} \cdot C \\
& \text { (growth) (death) (settling) }
\end{aligned}
$$

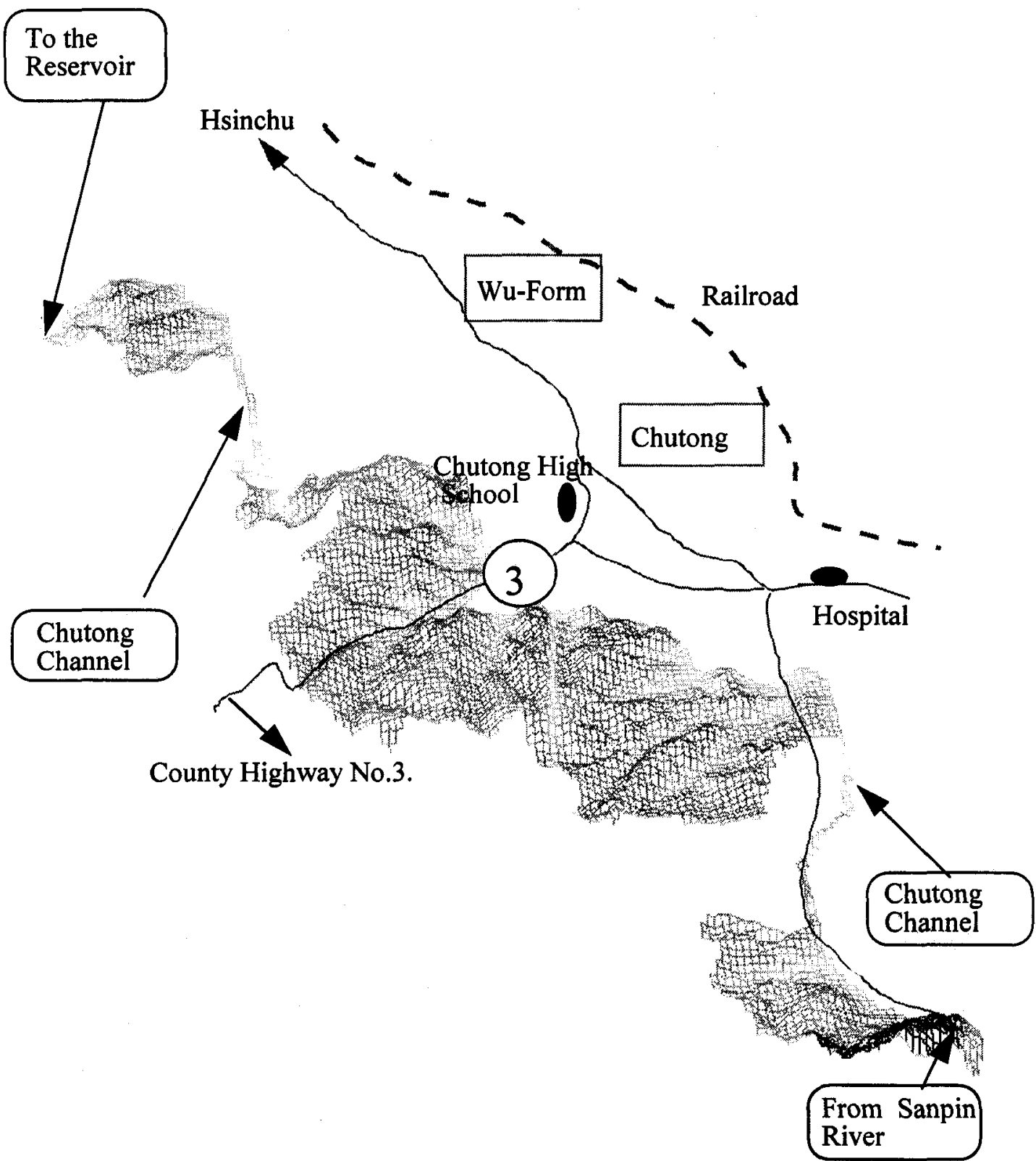

Fig. 1. Locations of Posan Reservoir and Chutong Channel. 


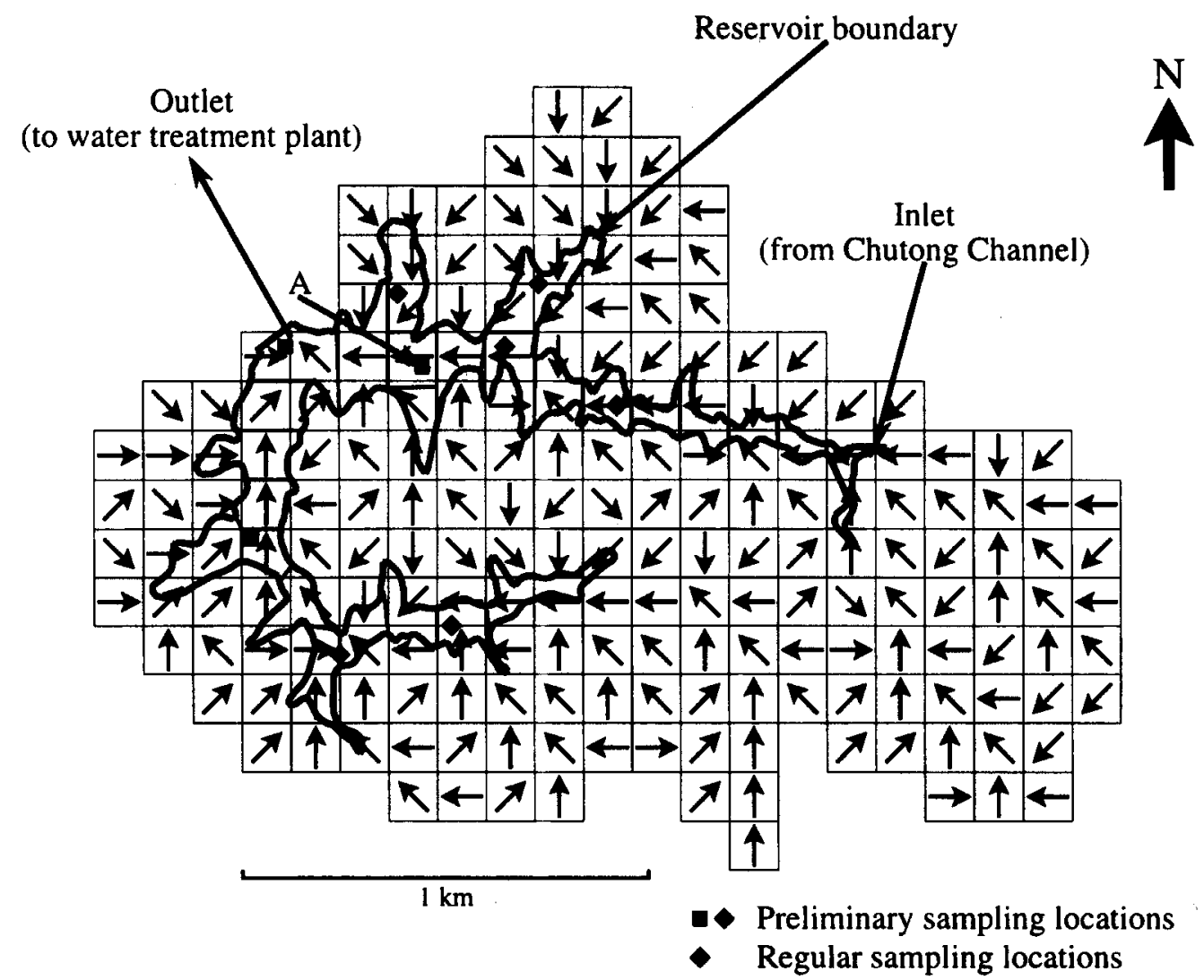

Fig. 2. AGNPS/WASP segmentation for Posan watershed.

$$
\begin{gathered}
\frac{\partial O P}{\partial t}=C_{\mathrm{d}} \cdot a_{\mathrm{pc}} \cdot f_{\mathrm{op}} \cdot C-P_{\mathrm{m}} \cdot \theta_{\mathrm{Pm}}^{T-20} \cdot\left(\frac{C}{h+C}\right) \cdot O P \\
\text { (mineralization) } \\
-\frac{V_{\mathrm{o}} \cdot\left(1-f_{\mathrm{dop}}\right)}{D} O P \\
\text { (settling) }
\end{gathered}
$$$$
\frac{\partial I P}{\partial t}=C_{\mathrm{d}} \cdot a_{\mathrm{pc}}\left(1-f_{\mathrm{op}}\right) C+P_{\mathrm{m}} \cdot \theta_{\mathrm{Pm}}^{T-20}\left(\frac{C}{h+C}\right) O P
$$$$
\text { (death) }
$$$$
\text { (mineralization) }
$$$$
-C_{\mathrm{g}} \cdot a_{\mathrm{pc}} \cdot \mathrm{C}
$$$$
\text { (growth) }
$$

where $a_{\mathrm{pc}}$ is phosphorus to carbon ratio (mg-P/mg-C), $O P$ is the organic phosphorus concentration, $P_{\mathrm{m}}$ is the dissolved organic phosphorus mineralization at $20^{\circ} \mathrm{C}$ (1/day), $f_{\mathrm{op}}$ is the fraction of dead and respired phytoplankton recycled to the organic phosphorus pool, $\theta_{\mathrm{Pm}}$ is temperature correction coefficient for $P_{\mathrm{m}}$, $h$ is the half saturation constant for phytoplankton limitation of phosphorus recycle (mg-C/liter); $V_{o}$ is the organic matter settling velocity $(\mathrm{m} / \mathrm{day}), f_{\text {dop }}$ is the fraction dissolved organic phosphorus, and $I P$ is the inorganic phosphorus concentration.
Benthic simulation. The benthos and water exchange phenomenon for phosphorus is simulated by the following three equations:

$$
\begin{gathered}
\frac{\partial I P}{\partial t}=d_{\mathrm{ana}} \cdot \theta_{\mathrm{ana}}^{T-20} \cdot a_{\mathrm{pc}} \cdot f_{\mathrm{op}} \cdot C-d_{\mathrm{op}} \cdot \theta_{\mathrm{op}}^{T-20} \cdot f_{\mathrm{dop}} \cdot I P \\
\text { (algal decomposition) } \\
\frac{\partial O P}{\partial t}=d_{\mathrm{ana}} \cdot \theta_{\mathrm{ana}}^{T-20} \cdot a_{\mathrm{pc}}\left(1-f_{\mathrm{op}}\right) C+d_{\mathrm{op}} \cdot \theta_{\mathrm{op}}^{T-20} \cdot f_{\mathrm{dop}} \cdot I P \\
\text { (algal decomposition) } \\
F_{i j}^{\mathrm{p}}=\frac{E}{D_{\mathrm{b}}}\left(P_{j} \cdot f_{j}-P_{i} \cdot f_{i}\right)
\end{gathered}
$$

where $d_{\text {ana }}$ is the anaerobic algal decomposition rate ( $1 /$ day), $\theta_{\mathrm{ana}}$ is the temperature correction coefficient for $d_{\mathrm{ana}}, d_{\mathrm{op}}$ is the organic phosphorus decomposition rate (1/day), $\theta_{\mathrm{op}}$ is the temperature correction coefficient for $d_{\mathrm{op}} ; F_{i j}^{\mathrm{p}}$ is the flux between waste benthic segment $j$ and water segment $i, E$ is the diffusive exchange coefficient, $D_{\mathrm{b}}$ is the benthic layer depth, $P_{j}$ is the phosphorus (IP or $O P$ ) concentration of benthic segment $j ; P_{i}$ is the phosphorus (IP or $O P$ ) concentration of water segment $i$, and $f_{j}$ and $f_{j}$ are the dissolved fractions. 


\section{Modeling segmentation}

For applying AGNPS and WASP, the watershed and water body must be divided into small model elements that are called grids for AGNPS and segments for WASP. The criteria for grid division include terrain variation, soil types, land uses, hydrological characteristics, etc. Smaller grids describe geographical data more precisely, but more computation time and data preparation effort are required. As a compromise, the grid size of $120 \mathrm{~m} \times 120 \mathrm{~m}$ was used in this study. The grid division with drainage pattern for Chutong and Posan reservoir watersheds are shown in Figs 2 and 3 , respectively. For Chutong channel, it was assumed that the open channel accepted and transported most external pollutants from storm runoff and, therefore, the portion of closed channels was excluded for modeling simulation.

Criteria for WASP segmentation for a water body include (1) minimizing the segment volume differences to diminish the possible numerical dispersion, (2) selecting appropriate size that can express the representative average of water-quality concentration

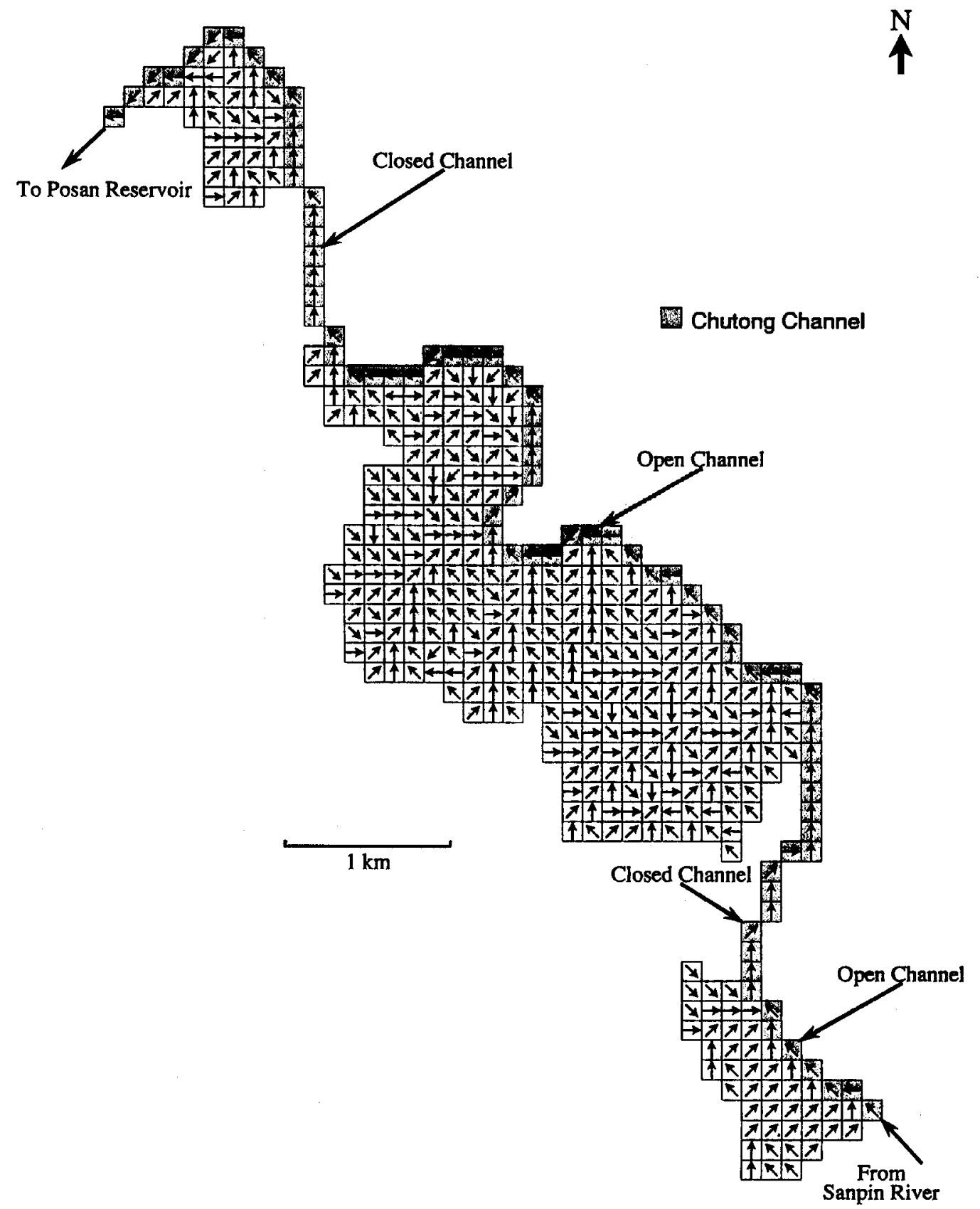

Fig. 3. AGNPS segmentation for Chutong Channel watershed. 
distribution, and (3) requiring vertical division if the stratification exists in the water profile. Moreover, and more important for this study, proper segmentation to coordinate with grids used by AGNPS can significantly reduce the difficulty of exchanging data between the models and, therefore, facilitate the model integration task. Finally, the boundaries of the upper layer of segments were made as close to the grid boundaries for AGNPS. The water body was divided into two layers because a distinct stratification existed at $8 \mathrm{~m}$ deep. The final segmentation of the water profile was divided into 46 segments, of which 26 were for the upper layer, as shown by the bold lines in Fig. 2, and 20 for the lower layer. With the layer for benthic segments below the lower water segments, a total of 66 segments were used.

\section{Data collection and model parameter preparation}

For external loading simulation by AGNPS, data collected in a previous study (Kao et al., 1994) were utilized. Numerous parameters are required for applying WASP. Data for WASP parameters mainly came from three sources: (1) experimental laboratory analysis under aerobic and marginal anaerobic conditions for possible ranges of organic phosphorus releasing rates, (2) theoretical estimation, and (3) data cited in previous similar studies (e.g. Bowie et al., 1985; Thomann and Mueller, 1987).

\section{SAMPLING PLANNING AND FIELD INVESTIGATION}

The field sampling plan included two stages of preliminary and regular samplings and three major parts of water, benthic sediment, and watershed. Preliminary sampling was implemented to realize water quality and pollution distribution for selecting appropriate regular sampling points. Water in the reservoir profile was sampled for both upper and lower layers. Two meters below the water surface and 1-2 $\mathrm{m}$ above the sediment surface were sampled. Ten sampling points selected for this stage are shown in Fig. 2. Phosphate-related and other parameters for all samples were analyzed. Five of the points, as shown in Fig. 2, were finally selected for weekly (water column) and bi-weekly (benthic sediment) regular sampling. Benthic sediment was collected using a gravity corer dropped from a boat. Water-quality parameters for pore water were analyzed similar to those for the upper or lower water column. Sediment was used for laboratory analysis described in the next section for estimation of releasing rates. Settling mass were collected by several sets of catchers. Each set of catchers were placed and lined up vertically within the water column; catchers were put about $3 \mathrm{~m}$ apart.

External load sampling for Chutong and Posan watersheds during two events were implemented. This task was difficult because it was hard to predict when a representative storm event would occur and sampling had to be done within a short period for collecting effective samples for analyzing the first flush pollutant load distribution, peak flow, and water-quality parameters. Samples were collected for 5-10 min during the first hour of the event, and few samples were collected after then. Sampling points were selected primarily based on land uses and geographical terrain and, of course, the manpower available to this research. One or two representative points were selected for each major land use.

\section{LABORATORY ANALYSIS FOR PHOSPHORUS RELEASING RATES}

The transfer mechanism between water bulk and the benthic sediment includes soluble phosphorus released from the solid phase of the sediment and physical movement of soluble phosphorus from the sediment to water phase. The phosphorus releasing rate may be affected by dissolved oxygen (DO), $\mathrm{pH}$ (Ku et al., 1978), ox-reduction potential (Andersen, 1982), microorganism (Jacoby et al., 1982), and transport mechanism (Freedman and Canale, 1977; Holdren and Armstrong, 1980). In this study, no significant $\mathrm{pH}$ variation was observed from field sampling.

Originally, it was thought that the sediment phase was under the anaerobic condition. From the field sampling results, however, it was under marginal anaerobic condition with low DO. The possible reason is that the reservoir is not deep enough to keep oxygen transfer away. Experiments were, therefore, set into two groups, one in marginal anaerobic and one in aerobic condition. Nitrogen was aerated to maintain the marginal anaerobic condition under $1 \mathrm{ppm}$ DO level, when the aerobic set was kept around $6 \mathrm{ppm}$ DO. All the experiences were prosecuted on a round rack with column tubes directly removed from the gravity corer. The release rates of ortho-phosphorus and TP for typical samples in April 1994 are listed in Table 1. In general, the release rates obtained from the anaerobic set were higher than those from the aerobic set. Few desorption results in the aerobic set and adsorption results in the anaerobic set were observed. These results indicate that other factors in addition to DO were important for determining the release rate. The study of the mechanism is, however, beyond the scope of this research and is currently under exploration.

Table 1. Phosphorus release rates $\left(\left(\mathrm{mg} / \mathrm{m}^{2}\right) /\right.$ day $)$ for sampling location $\mathrm{A}$

\begin{tabular}{lrrr}
\hline & 13 April & 14 April & 17 April \\
\hline Total phosphorus & & & \\
Aerobic group & 0.17 & 1.28 & -0.65 \\
Marginal aerobic group & 5.27 & 6.73 & 47.78 \\
Anaerobic group & 9.14 & 14.33 & 61.86 \\
POA & & & \\
Aerobic group & -2.86 & 2.17 & 1.47 \\
Marginal aerobic group & -2.02 & 12.83 & 45.94 \\
Anaerobic group & 14.95 & 12.12 & 58.07 \\
\hline
\end{tabular}


MODEL INTEGRATION, CALIBRATION, VERIFICATION AND SIMULATION

\section{External loading simulation by AGNPS}

The modeling simulation was implemented for the period of 26 January to 25 April 1994. During this period, there were 19 significant storm events. The model verification for the AGNPS model were implemented in two steps: (1) verification of the modeling result with benthic sediment change within 3 years, and (2) verification with data sampled in storm events. Although AGNPS is a physical-based model for which the calibration step is generally not implemented, many parameters used by AGNPS were collected from USA cases and might not be appropriate for the local characteristics. For example, the fertilizing pattern in Taiwan is different from that in the USA, and rainfall intensity effects for soil erosion differs significantly from that in the USA according to previous local research. Some model parameters were, therefore, adjusted based on local characteristics of the watersheds. The verification of the model is done first for sediment because detailed sedimentation data are available for the years of 1986-1988. After model parameters were specified from various geographical maps and field investigation, the model was implemented for 84 significant storm events during the 3 years. This verification was detailed by Kao et al. (1994). The total arrival amount of sediment from these events is approximately $17,783 \mathrm{t}$, that is about $82 \%$ of the actual change monitored during the 3 years. Possible reasons for the difference include that (1) the 3-years data were monitored after the reservoir was established and no investigation was carried out for the initial collapse of reservoir rims during the construction period; (2) gully sources were not adequate simulated because of no research available to verify the applicability of the AGNPS suggested parameters for local areas; and (3) events were simulated discretely instead of continuously due to the limitation of AGNPS for a single event only. The result is, however, good enough when compared with related local external (or nonpoint-source) loading research results. Model verification was then implemented further for sampled data from field investigation. Parameters related to sediment were not adjusted in this step, and parameters such as fertilizing level that related to water quality were adjusted based on values obtained from some previous local research.

\section{Integration of AGNPS and WASP}

Other than the grid/segment division, some other problems must be resolved in order to integrate both models. For water-quality parameters for phosphorus and nitrogen, WASP simulates orthophosphate, organic phosphorus, inorganic phosphorus, ammonia nitrogen, nitrate and organic nitrogen, while AGNPS handles only soluble phosphorus, phosphorus adsorbed in sediment, and TP. These nutrient parameters are not compatible for both models. Some conversion factors are, thus, determined based on hydrographs using a timeweighted approach. Water-quality parameter fractions in runoff of the sampled storm events for ortho-phosphate in the soluble phosphorus and the fractions of ammonia nitrogen, nitrate, and organic nitrogen in the TN were computed. Unfortunately, the fractions were not constants, and a flow-weighted average method based on the hydrograph was used to determine the factors. The conversion ratios, for the Posan and $\left\{\right.$ Chutong\} watershed, are $\mathrm{PO}_{4}-\mathrm{P}$ :organic$\mathrm{P}: \mathrm{TP}=0.743: 0.24: 1 \quad\{0.836: 0.12: 1\}$ and $\mathrm{NH}_{3}-$ $\mathrm{N}: \mathrm{NO}_{3}-\mathrm{N}: \mathrm{TN}=0.191: 0.388: 0.423$

$\{0.212: 0.328: 0.46\}$. The ratios for $\mathrm{PO}_{4}-\mathrm{P}$ and organic-P to TP are not summed up to one and are not adjusted because some poly-phosphorus or complex and laboratory analysis errors may exist. Other than the determination of the ratios, many intermediate computer programs were written to process the output files created by the two models to facilitate the integration and result presentation.

\section{Internal loading simulation by WASP}

The model built by WASP was first calibrated for water volume changes. Considering time and spatial factors, segment volumes were adjusted to get the results similar to the real storage volume change during a period of 3 months. For water-quality simulation, model parameters for non-phosphorus items were calibrated before adjusting model parameters for phosphorus-related items. External loads were obtained from the AGNPS model. The model was implemented dynamically for the calibration period between 26 January to 21 March 1994 and the verification period of 21 March to 25 April 1994. Figure 4 compares the simulated and sampled results for both calibration (days 1-55) and verification periods (days 55-90) for each segment where field samples are available. Segments indexed larger than 26 are bottom water segments. Figure 5 shows a similar comparison for spatial difference for day 28 during the calibration period. The simulated concentration for ortho-phosphate, organic-P, and other parameters are acceptable when compared with the field sampled data, although few over-estimations and under-estimations are observed.

\section{INTERNAL LOAD ESTIMATION}

Finally, the internal phosphorus load of the reservoir was estimated using the established dynamic model. The internal load was determined by the following equation based on dynamic modeling results:

Internal load

$$
=\sum_{t=1}^{k} \sum_{i=1}^{n}\left(v_{i, t} p_{i, t}-v_{i, t-1} p_{i, t-1}\right)-\sum_{t=1}^{k} \sum_{j=1}^{b}\left(w_{j, t}-p_{0 j, t}\right)
$$



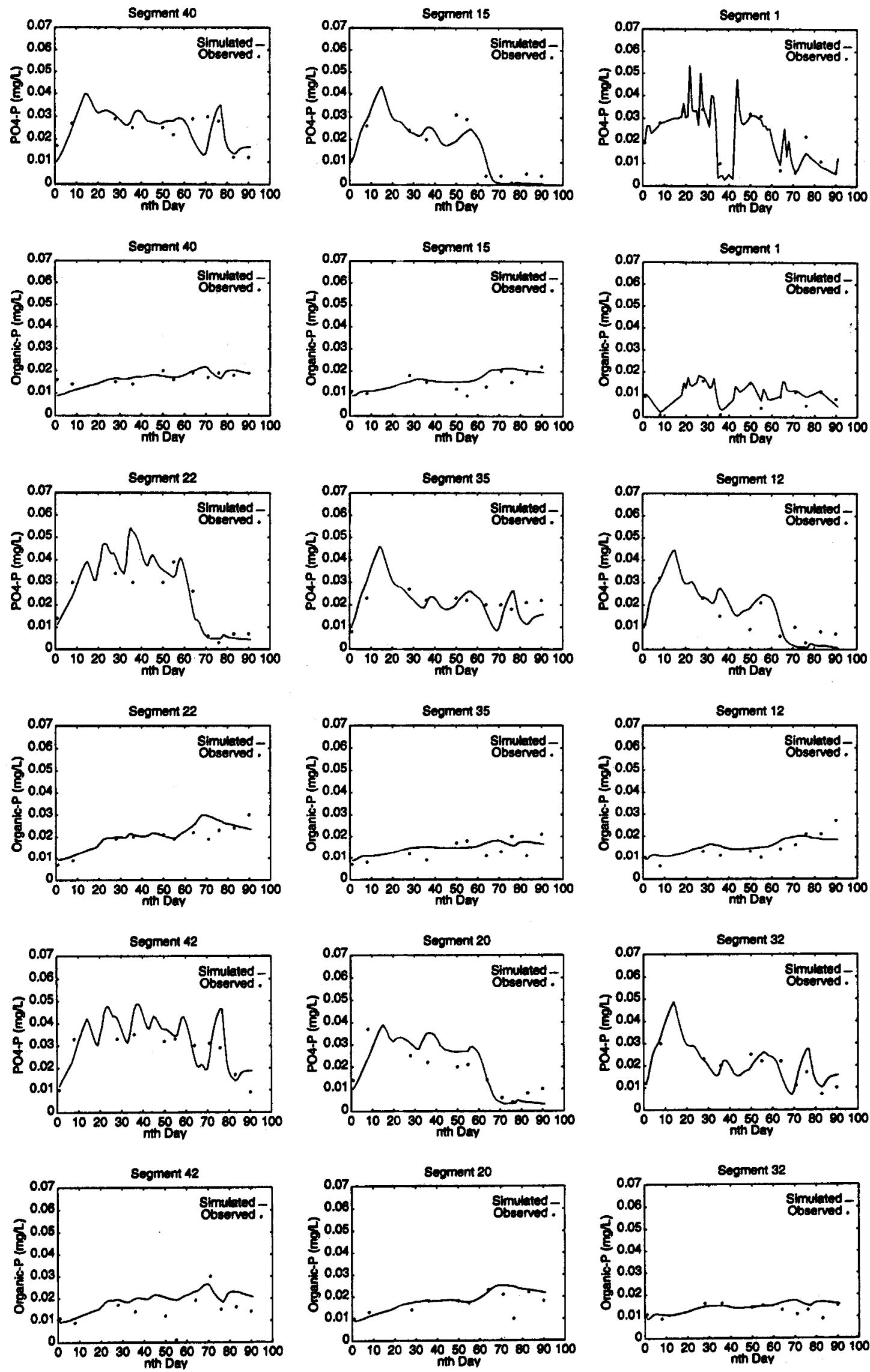

Fig. 4. Simulated vs observed data for each sampled WASP segment. 


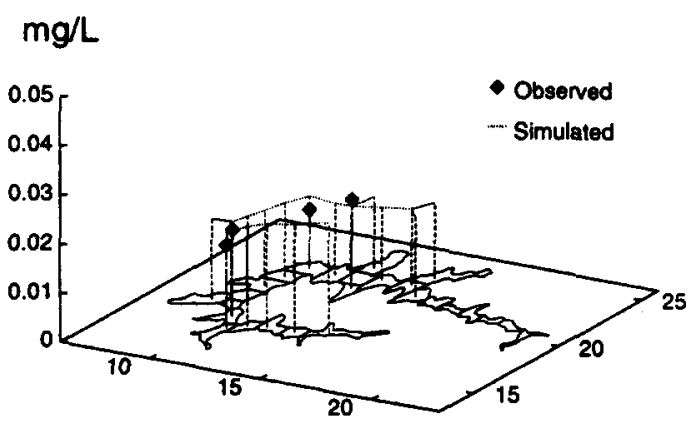

Organic-P (Day:28)(Bottom Segment)

$\mathrm{mg} / \mathrm{L}$

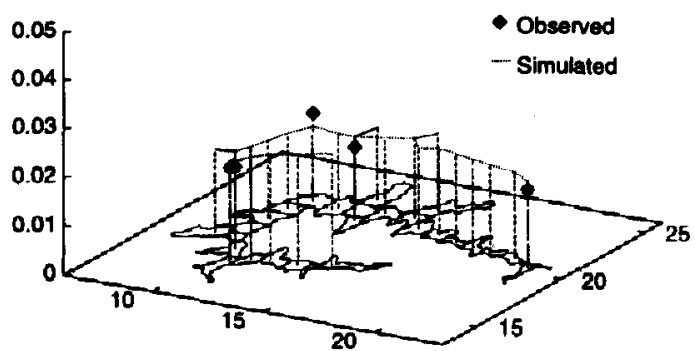

$\mathrm{mg} / \mathrm{L}$

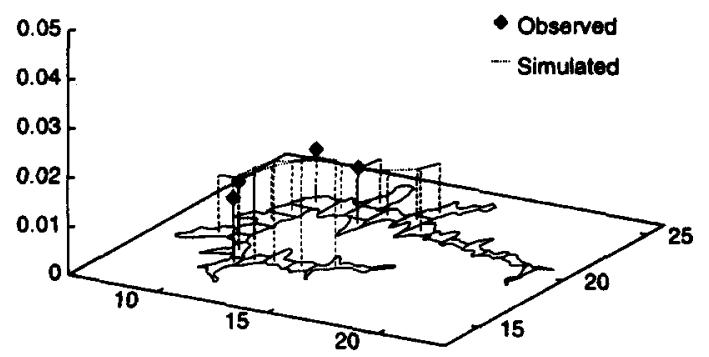

PO4-P (Day:28)(Bottom Segment)

$\mathrm{mg} / \mathrm{L}$

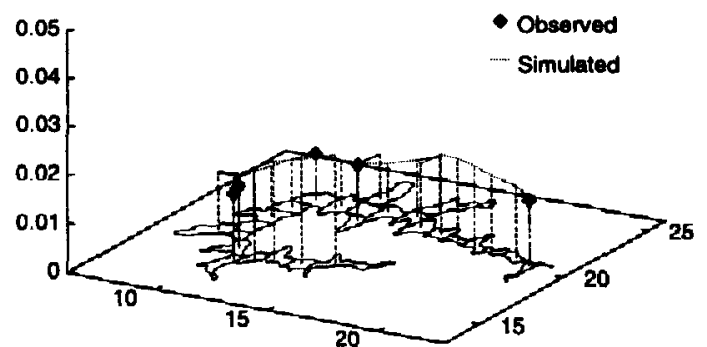

Fig. 5. Spatial comparison for simulated vs observed data for day 28.

where $k$ is the number of time intervals, $n$ is the number of WASP segments, $v_{i, 1}$ and $v_{i, t-1}$ are the volume of segment $i$ at time $t$ and $t-1$, respectively, $p_{i, r}$ and $p_{i, t-1}$ is the TP concentration of segment $i$ at time $t$ and $t-1$, respectively, $b$ is the number of boundary segments, $w_{j, t}$ is the external load entered into boundary segment $j$ at time $t$, and $p_{0, j, t}$ is boundary loss (including output) of boundary boundary loss (including output) of boundary segment $j$ at time $t$. For convenience, time intervals were all set to be equal to 1 day, although the model time $t$ and $t-1$, respectively, $b$ is the number of boundary segments, $w_{j, r}$ is the external load entered into boundary segment $j$ at time $t$, and $p_{0, j, t}$ is computation interval is smaller. The first term for mass changed within the water body is computed based on results shown in Fig. 6. The second term, listed as (A) and (B) in Table 2 for external loads and output loss, is computed based on results obtained from the AGNPS modeling output. The internal loads determined with this dynamic modeling approach are 41.74 and $1.59 \mathrm{~kg}$ for the calibration and verification periods.

\section{CONCLUSIONS}

In this article, a case study for the Posan off-stream reservoir is described to exemplify the utilization of

Table 2. Estimation of total phosphorus internal loads (kg)

\begin{tabular}{lrccc}
\hline & $\begin{array}{c}\text { Output } \\
\text { (A) }\end{array}$ & $\begin{array}{c}\text { External load } \\
\text { (Posan + Chutong) } \\
(\mathrm{B})\end{array}$ & $\begin{array}{c}\text { Net change } \\
(\mathrm{C})\end{array}$ & $\begin{array}{c}\text { Internal load } \\
(\mathrm{A})+(\mathrm{C})-(\mathrm{B})\end{array}$ \\
\hline Simple mass balance & & & & \\
Calibration period & 77.94 & 147.26 & 81.38 & 12.06 \\
Verification period & 32.13 & 87.38 & 48.20 & -7.05 \\
Entire period & 110.07 & 234.64 & 129.58 & 5.01 \\
$\begin{array}{l}\text { Dynamic modeling (from } \\
\text { Calibration period }\end{array}$ & 77.94 & 147.26 & & \\
Verification period & 32.13 & 87.38 & 111.06 & 41.74 \\
Entire period & 110.07 & 234.64 & 56.84 & 1.59 \\
\hline
\end{tabular}




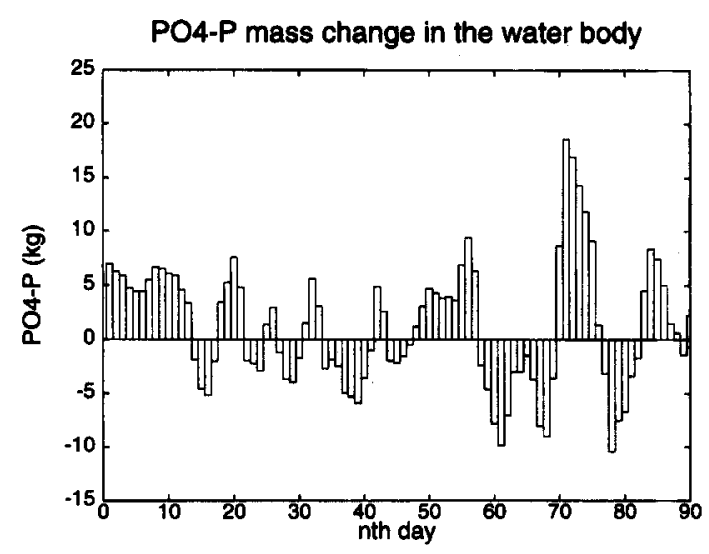

TP mass change in the water body

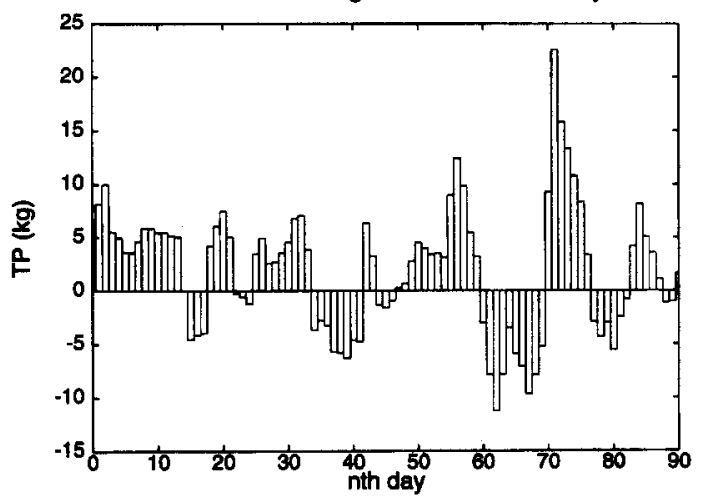

Fig. 6. Phosphorus mass change in the water body (computed based on dynamic spatial modeling results).

the proposed internal loading estimation procedure using a dynamic spatial model. The integration approach proposed for combining AGNPS and WASP makes it possible to simulate both internal and external loadings simultaneously with proper segmentation and determination of water-quality conversion ratios. The multiple step calibration and verification procedure demonstrated for the case study reduces the complexity of calibrating the numerous parameters of both models at the same time. The internal load estimation by the dynamic modeling approach with field investigation and laboratory analysis provides detailed variation. In addition to the overall trend, the spatial and temporal distribution of the results and parameters are available with the dynamic modeling approach, and these results are expected to provide insight into the system and, therefore, facilitate the planning for an efficient water-quality control strategy. The procedure, although it is primarily designed for the off-stream reservoir, is also applicable for other similar internal load estimation of a reservoir or lake.

Additional research, however, is necessary to explore further and to enhance the modeling estimation procedure. For example, the mechanism of phosphorus releasing rates for local reservoirs, appropriate model parameters that are applicable for local areas, a long-term comprehensive sampling plan for external loads, internal loads, and model parameters, and a single model for simulating both internal and external loads need to be studied in more detail, although research for these issues is expensive and manpower-intensive.

Acknowledgements-The authors thank National Science Council, Taiwan, Republic of China, for providing partial financial support (Grant No. NSC 82-0410-E-009-382). They acknowledge kind assistance from $\mathrm{Mr} \mathrm{R}$. B. Ambrose of US EPA. Many undergraduate students from the Civil Engineering and Applied Chemistry Department of National Chiao Tung University who helped in field investigations and laboratory analyses are greatly appreciated, although it is impossible to list all of them.

\section{REFERENCES}

Ambrose R. B., Wool T. A. and Martin J. L. (1993) The water quality analysis simulation program, WASP5: model documentation and input dataset. Environmental Research Laboratory, US EPA, Athens, GA.

Andersen J. M. (1982) Effect of nitrate concentration in lake water on phosphate release from the sediment. Wat. Res. 16, 1119-1126.

Bowie G. L., Mills W. B., Porcella D. B., Campbell C. L., Pagenkoph J. R., Rupp G. L., Johnson K. M., Chan P. W. H. and Gherini S. A. (1985) Rates, constants, and kinetics formulations in surface water quality modeling, EPA/600/3-85/040, 2nd edn. US EPA.

Carlson R. E. (1977) A tropic state index for lakes. Limnol. Oceanogr. 22, 361-369.

Dillon P. J. and Evans H. E. (1993) A comparison of phosphorus retention from mass balance and sediment core calculations. Wat. Res. 27, 659-668.

Freedman P. L. and Canale R. P. (1977) Nutrient release from anaerobic sediments. ASCE J. Environ. Engng 104(EE2), 233-244.

Holdren G. C. and Armstrong D. E. (1980) Factors affecting phosphorus release from intact lake sediment cores. Environ. Sci. Technol. 14(1), 79-87.

Istvanovics V. (1988) Seasonal variation of phosphorus release from the sediments of shallow lake Bakaton (Hungary). Wat. Res. 22, 1473-1481.

Jacoby J. M., Lynch D. D., Welch E. B. and Perkins M. A. (1982) Internal phosphorus loading in a shallow eutrophic lake. Wat. Res. 16, 911-919.

Kao J.-J., Tsai M. C. and Bau S. F. (1994) Development of analysis models for total mass load based discharge programs (I), NSC 81-0410-E009-382. Report to ROC National Science Council, Taipei, Taiwan, R.O.C.

Ku W. C., Digiano F. A. and Feng T. H. (1978) Factors affecting phosphate adsorption equilibria in lake sediments. Wat. Res. 12, 1069-1074.

Rossi G. and Premazzi G. (1991) Delay in lake recovery caused by internal loading. Wat. Res. 25, 567-575.

Thomann R. V. and Mueller J. A. (1987) Principles of Surface Water Quality Modeling and Control. Harper \& Row, New York.

Wischmeier W. H. and Smith D. D. (1978) Predicting Rainfall Erosion Losses, Arg. Handbook 537. US Department of Agriculture, Washington, DC.

Wu S.-C., Wang, M.-S. and Chen S.-Y. (1992) Mass balance and control strategy for reservoirs in Taiwan. Report to ROC EPA, (in Chinese), Taipei, Taiwan, R.O.C.

Young R. A., Onstad C. A., Bosch D. D. and Anderson W. P. (1987) AGNPS, agricultural non-point source pollution model. USDA-ARS, Morris, MN. 